\title{
Correction to: Effect of brominated flame retardant on the pyrolysis products of polymers originating in WEEE
}

\author{
Maria Anna Charitopoulou ${ }^{1} \cdot$ Lambrini Papadopoulou $^{2} \cdot$ Dimitrios S. Achilias $^{1}$ (D)
}

Published online: 11 August 2021

(C) Springer-Verlag GmbH Germany, part of Springer Nature 2021

Correction to: Environmental Science and Pollution Research https://doi.org/10.1007/s11356-021-15489-8

The paper contains strike through text that should be removed.

The original article has been corrected.

Publisher's note Springer Nature remains neutral with regard to jurisdictional claims in published maps and institutional affiliations.

The online version of the original article can be found at https://doi.org/ 10.1007/s11356-021-15489-8

Dimitrios S. Achilias

axilias@chem.auth.gr

1 Laboratory of Polymers and Dyes Chemistry and Technology, Department of Chemistry, Aristotle University of Thessaloniki, 541 24 Thessaloniki, Greece

2 Department of Mineralogy-Petrology-Economic Geology, Aristotle University of Thessaloniki, GR-54 124 Thessaloniki, Greece 